\title{
NOTAS SOBRE UNA HERENCIA
}

\begin{abstract}
Álvaro Enrigue
En este artículo se plantea que aun cuando la producción literaria más impactante de Mario Vargas Llosa se concentra en los primeros años de su carrera de escritor - entre La ciudad y los perros y Conversación en La Catedral-, el aprendizaje técnico de ese primer periodo deslumbrante incidió en su trabajo concediéndole la libertad formal que le permitiría emprender proyectos menos vistosos, pero tal vez más influyentes en la literatura latinoamericana posterior al boom. De entre esas novelas, La tía Julia y el escribidor — señala Á. Enrigue - puso en juego formas y valores que, con los años, se transformarían en el discurso dominante de la literatura en la región.
\end{abstract}

Álvaro Enrigue (México, 1969). Autor de las novelas La muerte de un instalador (1996), El cementerio de las sillas (2002), Vidas perpendiculares (2008) y Decencia (Anagrama, 2011), y de los libros de cuentos Virtudes capitales (1998) e Hipotermia (2006). Profesor de literatura de la Universidad Iberoamericana. Alvaro.enrigue@gmail.com.

Estudios Públicos, 122 (otoño 2011). 


\section{$\mathrm{H}$}

curso cuyo premio eran muchísimos euros y un año de tutoría de Mario Vargas Llosa - un año durante el cual el ganador escribiría una novela asistiendo a sesiones de trabajo en entornos cuajados de glamour: Nueva York, Madrid, Lima, Washington DC.

Hasta donde entendí - hay periodos de la vida en que uno no entiende nada - un grupo amplio de especialistas elegía a un número grande de escritores por entonces jóvenes, otro más reducido seleccionaba a tres finalistas y esos tres asistían a una entrevista con Vargas Llosa, tras la que él elegía al que sería su laborioso interlocutor por doce meses.

No gané, no salí en el New Yorker, no me dieron la beca que quién sabe hacia dónde habría conducido mi vida - seguro al mismo sitio en que está ahorita-, pero tuve un privilegio extraño: como la entrevista sucedía en viernes, en lugar de ir a cenar a un restorán con don Mario, como habían hecho los otros dos candidatos, fui a su casa, donde después de una conversación más o menos profesional, ofrecía una cena para la que, me señalaron claramente los patrocinadores, yo no estaba considerado.

La conversación con Vargas Llosa sucedió en la sala de su casa, con vino y botana - un contexto definitivamente inesperado para un evento que por más literario que fuera no dejaba de tener el sabor de una entrevista de trabajo. Hablamos con una frescura de su parte que me impresionó mucho. Por entonces yo nunca había platicado con una leyenda viviente de la literatura y no sabía que los escritores famosos de verdad son los únicos que no están conscientes de su gloria. Conversamos de narrativa mexicana reciente, de la generación del 32 - le interesaban particularmente Salvador Elizondo y Sergio Pitol-, de la academia norteamericana. Me impresionó mucho su interés por lo menudo: el hecho de que no hablara con la grandilocuencia de una estrella de rock, sino con el detalle del que se pasea con frecuencia por las librerías y está al tanto de lo que está sucediendo en las literaturas regionales. Sobre todo, me impresionó su curiosidad: a través de una serie de preguntas cándidas me fue guiando para que hiciera una radiografía de la literatura mexicana más joven y poniéndola en relación con lo que estaba sucediendo en Barcelona, en Santiago, en Buenos Aires. 
Cuando faltaba poco para la hora en que el estricto protocolo de los patrocinadores señalaba que me tenía que levantar y despedirme, me recomendó una librería. Le dije que ya había estado ahí y me preguntó qué había comprado. Le hice una lista que incluía a César Moro. Fue mi maestro de Francés en el Leoncio Prado, me dijo. Y yo, que entre el vino y su afabilidad me había olvidado un poco de que platicaba con Mario Vargas Llosa sentí un mareo bestial: estaba con el autor de La ciudad y los perros, una novela tan inhumanamente perfecta y tan influyente en mi propia vocación que hasta entonces me había parecido nacida, como Palas Atenea, sin intervención de madre y con las armas puestas.

Mario Vargas Llosa publicó La ciudad y los perros en 1963, a los 25 años. Su siguiente novela fue La casa verde (1966), luego Conversación en La Catedral (1969). Se puede seguir sin pausa: La tía Julia y el escribidor, La guerra del fin del mundo, Historia de Mayta, La fiesta del Chivo - por hablar sólo de sus libros extraordinarios. No toda su producción novelística es pareja: entre esos libros deslumbrantes - Borges quería sólo una página que lo justificara, no seis o siete novelas de largo aliento - hay volúmenes con momentos brillantes - como la tirada de Elogio de la madrastra (1988) y Los cuadernos de don Rigoberto (1997) - y libros que se habrían beneficiado de un poco de serenidad: Travesuras de la niña mala (2006) o la recientísima El sueño del Celta (2010) tienen ratos que requerían de un editor que no se arredrara ante el figurón que gravitaba sobre el original en corrección.

A la sombra de estos títulos cuya llegada a mesas de novedades siempre termina siendo un acontecimiento - Vargas Llosa supone para sus lectores una suerte de calenda vital: mi vida adulta completa ha sido regida por lo lapsos en que estoy leyendo su libro nuevo - crece una notable obra crítica, esa sí consistente en su calidad, y volúmenes de poética y teatro tal vez más caprichosos que disfrutables.

Vargas Llosa es tan un hecho en nuestras vidas de lectores y su carrera está tan imbricada con el momento en que la novelística hispanoamericana dejó de ser un fenómeno regional — no hay que olvidar que para la generación anterior a la de los autores del boom y todas las que les antecedieron la Literatura con mayúscula era un fenómeno irremediablemente asociado a la lectura de traducciones-, que tal vez hayamos perdido la habilidad para notar su peculiaridad con respecto al grupo de autores del subcontinente con los que irrumpió en la escena 
literaria mundial: es un realista de cepa pura, beneficiado sólo formalmente por las epopeyas experimentales del siglo XX.

A pesar de que desarrolló su carrera en un contexto en el que el ejercicio de un estilo desbordado era considerado indispensable para un escritor de América Latina, me parece que Vargas Llosa nunca ha aspirado a más que plantear de manera eficaz y transparente un vasto fresco social sobre el tiempo que le tocó vivir. Su literatura está enmarcada siempre por una preocupación que se define en la célebre idea inicial de Conversación en La Catedral: “Cuándo se jodió el Perú?”. La experiencia, la lectura, el paso de los años del que todos somos tan poco responsables hizo el resto: su ánimo testimonial radió de la Lima de su adolescencia hacia todo el mundo: ¿cuándo se jodió el Congo?, ¿cuándo París?, ¿cuándo Santo Domingo?

No es ninguna novedad que Vargas Llosa escriba sobre climas globales. La fiesta del Chivo sucedía enteramente en República Dominicana, La guerra del fin del mundo en Brasil, El Paraíso en la otra esqui$n a$ entre Francia y Tahití. La calidad transparente de su prosa — sobria y franca-, y su gusto por las tramas en las que los contenidos simbólicos de la novela se desarrollan sin menoscabo de una historia que avanza de A a B sin darle aliento al lector, le han permitido siempre trabajar con absoluta libertad sobre los temas y personajes que le interesan. No depende de las hablas, los contextos, los ritmos característicos de ninguna región. Es el tipo de autor que sobrevive intacto a las traducciones porque su escritura está más centrada en la precisión que en el estilo, en la estructura narrativa que en lealtad a una mitología local.

Lo anterior, naturalmente, contradice al curioso sabor mundialista que permeó al Nobel que Vargas Llosa aceptó el diciembre pasado en calidad de escritor global. ¿Por qué nos honra tanto a los mexicanos que Octavio Paz lo haya recibido en el noventa o a los chilenos que tengan dos en su haber, si no hay una distinción más individual que ésta? ¿Por qué les enoja tanto a los gringos que no se lo hayan dado a Philip Roth? El prestigio y la emoción del Nobel de Literatura sólo se pueden explicar por lo caprichoso e irracional de su selección anual — que el año pasado nos pareció justo sólo a los latinoamericanos de postura política moderada.

En los treinta años que separan a 1980 de 2010, el premio ha sido concedido cuatro veces a autores que escriben en español. De los cuatro ganadores tres fueron de Hispanoamérica. La alegría provinciana 
que genera esa estadística deja un resabio crudo en la boca. Premiado Vargas Llosa, Fuentes parecería salir de la carrera, Onetti y Donoso - que habrían sido mis favoritos - nunca fueron realmente competitivos. ¿Nos queda detrás de ellos un narrador global? Hay poetas en la región que podrían achicar en las listas de los años por venir, pero con el discurso de aceptación de diciembre pasado se cierra medio siglo de oro para la novela latinoamericana: no parece quedarnos ningún autor que pueda competir.

La aportación de Vargas Llosa a la literatura de la segunda mitad del siglo veinte viene de un gesto virtuoso que se cumple en sus mejores libros: el tiempo y la imagen nunca corren de manera lineal: se superponen en carreteras paralelas que a ratos se cruzan, se dividen, se trepan unas sobre las otras formando segundos, terceros y cuartos pisos, todos corriendo en la misma dirección pero en distintos años y paisajes. En Los cuadernos de don Rigoberto, por ejemplo, hay párrafos imposibles en los que cada frase atiende a una escena y una anécdota distintas, que sucedieron en diferentes momentos, y que no forman un laberinto, sino un mandala de trazo claro y sereno: aclaran, que es lo que siempre debería hacer un escritor.

Además Vargas Llosa es una persona que dice lo que piensa y asume sus consecuencias. Sus visitas a México son célebres porque - hasta la más reciente, que no tuvo gracia por ser sólo de aclamación mutua ente el autor y las autoridades - siempre se las arreglaba para poner el dedo en la llaga. Decía cosas incomodísimas como quien comenta un partido de fútbol, con el agregado que además lo que decía solía ser verdad. No es exagerado decir que nuestra airosa transición a la democracia pasó en parte por una adición mariana al diccionario político local: definió conspicuamente en televisión nacional y durante una transmisión en vivo al gobierno monolítico del PRI como una dictadura tan perfecta que era más bien una "dictablanda".

También es un hombre consistente: El discurso leído por Vargas Llosa al recibir el Premio Rómulo Gallegos en 1967 por La casa verde es un testamento sobre la claridad de sus ideas. Algunas de sus convicciones del periodo se han modificado sustancialmente, pero las que resisten son tantas, que tal vez lo que haya cambiado es el mundo y no él. En el texto de recepción del Rómulo Gallegos se quedaron empolvándose Sartre, la relatividad moral y el socialismo, pero todo lo demás siguió igual en el del Nobel: la palabra es acción indisociable de la 
afirmación política; la literatura sigue siendo pura crítica; la capacidad de la novela para influir socialmente le parece inobjetable, y el oficio de escritor, impensable sin una rigurosa militancia ética y un culto duro por el valor supremo de la libertad.

Esa consistencia sin diques es probablemente el nudo que sostiene la inteligencia de sus libros. Ninguno de los personajes de sus grandes novelas es nunca banal ni está ahí para entretener: han sido creados con una admirable economía que los vuelve entrañables y reveladores al mismo tiempo.

Hace unos años me dediqué a saquear ordenadamente a Vargas Llosa con fines utilitarios. Eran los finales de los años noventa y yo estaba escribiendo una novela que contaba una sola historia separada en tiempos y espacios muy distantes. Como estaba atorado con la forma, pensé en copiar lo mejor que pudiera sus despliegues estructurales, que me habían deslumbrado en las lecturas virginales que hice de sus libros antes de suponer que yo mismo sería escritor. Me senté a leerlo en orden y - me honra reconocerlo — con la plancha tibia a un lado.

Terminé la relectura de Conversación en La Catedral con la sensación de que para 1969 —el año en que se publicó y yo nací- ya no se podía exigir nada más de él. En 1962, con La ciudad y los perros había conseguido un fulgor stendhaliano para reflejar exteriores en la concentrada interioridad de su personaje principal. En 1965 había dictado cátedra balzaciana sobre la realidad del Perú con La casa verde _ justamente la novela que orilló a Carmen Balcells a convertirse en agente literaria tras de leer las primeras 40 páginas - y para el 69 había revolucionado la manera de contar en español con esa cosa monumental que es Conversación, cuya estructura sigue siendo un misterio.

A partir de esa novela, el tiempo se transformó, para la literatura en español, en una sustancia flexible y en un elemento dramático tan importante como la anécdota o los personajes. Ricardo Piglia ha dicho que antes de enjuiciar críticamente a un autor, hay que distinguir las razones técnicas por las que eligió una trama. A partir de Conversación en La Catedral quedó claro que los recursos de Vargas Llosa para construir un relato eran, simplemente, infinitos.

Vargas Llosa ha sido el analista más perceptivo y cruel de los desastres latinoamericanos y sus emanaciones, pero también el que mejor ha visto las fracturas del mundo en que florece el sentido: la ternura de 
los que no tienen nada más que lealtad a lo que son, la belleza de los que se hundieron desafiando a los poderes de su tiempo.

Es, sin embargo, uno de sus libros menos celebrados el que me parece que ha terminado por ser más influyente en las generaciones de autores más jóvenes de la región. Lo que me cimbró de La tía Julia y el escribidor (1977) la primera vez que la leí —a caballo muy pasado-, fue su condición visionaria.

El memorable Varguitas - personaje que anilla el relato de $L a$ tía Julia y el escribidor - vive una encrucijada, pero es tan joven que apenas lo nota; estudia Derecho y no quiere ser abogado; está en Lima y desespera por vivir en París; tiene un trabajo como periodista que utiliza para escribir cuentos - al parecer pésimos-; vive con sus abuelos convencido de que ya es un hombre. La novela relata la historia de su salvación a manos de dos almas excéntricas que nadie elegiría como norte: Pedro Camacho, prodigioso autor y director de radionovelas que ya perdió la razón pero nadie lo ha notado - una creatura de marcada filiación cervantina y flaubertiana-, y Julia, la tía política de Varguitas, quince años mayor que él, con quien vive una ardorosa historia de amor. Gracias a la enloquecida seriedad con que el guionista se toma su vocación de autor y a la violencia hacia las convenciones que supone un romance incestuoso, Varguitas descubre que la resignación no es un valor y que el centro no está donde las expectativas de la clase media, sino en el margen desde el que un personaje elige ver el mundo.

Tengo la impresión, pero tendrían que confirmarla los que recuerden algo más del año 77 que el patio de la primaria, de que La tía Julia y el escribidor fue una novela difícil de situar en el momento de su publicación. Todavía hace unos pocos años un lector profesional y disciplinado, pero demasiado serio para ser considerado inteligente, me repitió para definirla que era un "divertimento"; categoría más bien pedante y metafísica que casi siempre dice más sobre quien la emite que sobre el objeto que trata de iluminar.

Para 1977 Cortázar había dejado de dar golpe hacía años, pero Carlos Fuentes había publicado muy recientemente su novela más dura, Terra nostra, y salieron de manera más o menos simultánea Palinuro de México de Del Paso y la póstuma Oppiano Licario, de Lezama; José Donoso estaba preparando la edición de su libro más rabiosamente político: Casa de campo (1978), y Onetti escribía Dejemos hablar al viento (1979). Se respiraba todavía en el panorama literario latinoamericano 
un ambiente de ultramodernidad, sospecho que agarrada ya para entonces con las uñas de los preceptos que la universalizaron: la noción bajtiniana de polifonía, el uso de modelos tomados del noveau roman, la extenuación neobarroca, la idea (perdón, pero esa sí risible) de la novela total - yo prefiero el concepto tardío y más razonable propuesto por el propio Vargas Llosa: "novela de sillón".

Un poco más acá de los respetabilísimos relumbrones que la acompañaron en su lanzamiento en librerías, La tía Julia y el escribidor dialogaba con otra sensibilidad de lo literario: es la novela que ejemplifica un cambio cuántico en la percepción regional sobre cómo se narra y qué vale la pena de ser narrado. No es casual — en este sentido - que su epígrafe sea de Salvador Elizondo, ni que el volumen de la literatura continental con el que habría podido dialogar formalmente de manera más fluida en ese momento fuera de Manuel Puig _-El beso de la mujer araña es del 76.

Todos los elementos que con el tiempo definirían a las letras hispánicas de la transición entre dos siglos - y que asociamos con escritores cuyo reconocimiento fue posterior al boom- se hallan en La tía Julia y el escribidor. Está la subida al altar de lo literario de géneros sin prestigio - la radionovela y el melodrama cinematográfico. También la venenosa y delicada confusión de identidades entre el narrador del relato y el autor del libro. Hay la distancia irónica con respecto a la escritura, que desembocó en la transformación de la categoría del "estilo" en una noción flexible: un autor puede tener tantos estilos como libros. La definición de la realidad como un manto preñado irremediablemente de mediatización - el mundo definido por emociones estandarizadas por el influjo de los medios masivos. La interdependencia de los relatos novelísticos: narraciones que sin correr paralelamente sólo significan plenamente por los vasos que las comunican. La indefinición genérica como principio: ¿novela?, ¿memorias?, ¿libro de cuentos desaforados? Todo a la vez, todo el tiempo.

Hace años, en Perú, me levanté de la sala de los Vargas Llosa a las diez para las ocho, como resorte: era la hora en que los patrocinadores me habían dicho que me tenía que salir de su departamento. Me despedí con la formalidad y el pudor de un niño de colegio católico. ¿Tienes amigos en Lima?, me preguntó Mario un poco extrañado. Por entonces no los tenía, así que le respondí que no. ¿Dónde vas a cenar? En el hotel. Entornó los ojos y me obligó a sentarme de nuevo. Hay 
un coche esperándome abajo, le dije, omitiendo educadamente que el coche estaría lleno de patrocinadores viendo el reloj. Ahora alguien les avisa que nosotros te llevamos.

A las mil de la noche, después de una cena espléndida, todavía fuimos a un salón de baile popular, en el que varias personas de extracción muy humilde se le acercaron para disculparse por no haber votado por él en las elecciones en que perdió contra Fujimori. Al final él mismo y su hija me llevaron al hotel en el coche más normal del mundo. Vargas Llosa iba en el asiento del copiloto, virado de espaldas mientras conversaba entusiasmado sobre sus primeros durísimos años en París, y cómo había tenido que ganarse el sustento bailando en el metro con la tía Julia las canciones criollas que yo mismo le había visto ejecutar con donaire un poco antes. La historia no era nueva para mi - la cuenta en El pez en el agua-, pero tuvo el encanto de cumplir, a su manera, la promesa de la novela del escribidor: la literatura que se escapa del libro y gana realidad -el proyecto ideal de cualquiera que se haya dedicado a escribir seriamente después de los años ochenta. 